\title{
Parties Are No Civic Charities: Voter Contact and the Changing Partisan Composition of the Electorate*
}

\author{
Florian Foos ${ }^{\dagger} \quad$ Peter John ${ }^{\ddagger}$
}

Forthcoming in Political Science Research and Methods

\begin{abstract}
In contrast to non-partisan GOTV campaigns, political parties do not aim to increase turnout across the board. Instead, their principal goal is to affect the outcome of an election in their favor. To find out how they realize this aim, we carried out a randomized field experiment to evaluate the effect of campaign visits and leafleting by Conservative Party canvassers on turnout in a marginal English Parliamentary constituency during the 2014 European and Local Elections. Commonly-used campaign interventions, leaflets and door-knocks, changed the composition of the electorate in favor of the Conservative Party, but did not increase turnout overall. Supporters of rival parties, particularly Labour self-identifiers, were significantly less likely to mobilize in response to Conservative campaign contact than Conservative supporters. In contrast to the non-partisan GOTV literature, we show that impersonal campaign leaflets were as effective in shaping the local electorate in the Conservative's favor as personal visits. The common practice of contacting all constituents irrespective of their party preferences was effective as a campaign tactic, but had no civic benefits in the aggregate.
\end{abstract}

${ }^{*}$ Replication code and data are available at http://dx.doi.org/10.7910/DVN/EWISS3. The authors are very grateful to Jacob Rees-Mogg MP for agreeing to host the study in North East Somerset, and to the constituency workers and canvassers for delivering the intervention and collecting the data so efficiently. The article was first presented at the Midwest Political Science Association Conference, Chicago, April 2015, Panel 23-6 'What Works Best? Field Experiments Comparing Mobilization Tactics.' We thank the participants, in particular the discussant, Lisa Bryant, for their comments. We also thank Don Green for his valuable comments on an earlier draft of the paper and Alex Coppock for advice on the statistical analysis. We are also grateful to three anonymous reviewers and the editor for their close attention to the manuscript.

${ }^{\dagger}$ Department of Political Science, University of Zurich, Affolternstrasse 56, 8050 Zurich, Switzerland, foos@ipz.uzh.ch

${ }^{\ddagger}$ Department of Political Science, University College London, The Rubin Building, 29/31 Tavistock Square, London WC1H 9QU, United Kingdom, peter.john@ucl.ac.uk 
Rather surprisingly, the key findings from non-partisan Get Out the Vote (GOTV) campaigns - that campaign interventions have civic benefits by increasing electoral participation, and that personalized interventions are more effective than impersonal contact methods (Green and Gerber 2008; Green, Aronow, and McGrath 2013) - do not fully generalise to partisan campaigns. In spite of using similar contact methods, such as canvassing, telephone calls and leafleting, extant field studies randomizing contact with a partisan campaign show mixed results Arceneaux 2007; Doherty and Adler 2014; Nickerson, Friedrichs, and King 2006; Green 2004; Kendall, Nannicini, and Trebbi 2014; Bailey, Hopkins, and Rogers 2016 . Huber and Arceneaux 2007, Barton, Castillo, and Petrie 2014). Green, Aronow, and McGrath (2013) conclude from their meta-analysis of 79 experiments using non-partisan direct mail and 31 experiments using advocacy-direct mail, including both party-and issue-based endorsements, that the effects of non-partisan mailings and advocacy mailings differ significantly. While non-partisan direct mail on average has a positive effect on turnout, advocacy mailings have a negative, but statistically insignificant effect. It is particularly striking that field experiments that randomize partisan contact at the aggregate level have consistently failed to show an increase in voter turnout (Ramiro, Morales, and Jiménez-Buedo 2012, Pons 2014; Pons and Liegey 2016, Kendall, Nannicini, and Trebbi 2014).

To conclude from these mixed results that partisan campaigns are ineffective at influencing turnout is to misunderstand the goal of political parties when they make contact with voters. In contrast to non-partisan campaigns, political parties are not civic charities. They do not aim to increase turnout across the board (Gerber 2004; Holbrook and McClurg 2005 . Nickerson 2005). Instead, parties want to change the outcome of an electoral contest and there are different strategies of achieving this goal. Of course parties can act strategically and target GOTV efforts at party supporters or at places with the greatest density of support in a targeted mobilization strategy. In reality, most parties in countries other than the United States and Britain cannot follow this campaign strategy because they do not have access to valid and reliable data that would allow them to discriminate effectively between 
their supporters and opponents in the electorate. It is therefore no surprise that campaign experiments conducted with political parties in France, Spain and Italy have consistently failed to show positive effects on turnout (Ramiro, Morales, and Jiménez-Buedo 2012; Pons 2016; Pons and Liegey 2016, Kendall, Nannicini, and Trebbi 2014).

Even in the United States and Britain, where campaign targeting and canvassing is more advanced than elsewhere, it may explicitly make sense to include supporters of rival parties as targets of campaign interventions, assuming that campaign communication can win over voters or reduce turnout amongst those unlikely to support the party or candidate. For political parties and candidates, the key is to change the composition of the electorate, not to increase turnout. Many real-world campaign interventions include a double-edged appeal both to turnout and to vote for a particular candidate or party (for a discussion, see Nickerson, Friedrichs, and King 2006, p. 86). However, in spite of experimental results pointing to the possibility that political preferences might condition mobilization effects (McNulty 2005 . Shi 2015; Foos and de Rooij 2016), the large majority of field experiments that randomize contact at the aggregate (Pons 2014; Kendall, Nannicini, and Trebbi 2014) or the individual level (Nickerson 2005; Nickerson, Friedrichs, and King 2006) have problems identifying heterogeneous mobilization effects conditional on pre-intervention party support. At the aggregate level, null effects might mask that the intervention mobilized party supporters, but demobilized opponents. This possibility is of course particularly pronounced in multiparty systems such as Britain, France, Germany, Spain and Italy, where supporters of one particular party make up a smaller fraction of the electorate.

Aiming to throw more light on the effects of partisan campaign interventions on the partisan composition of the electorate, this paper reports results from a Conservative Party ground campaign using personal door-to-door visits and impersonal leaflets. The research site is the English town of Keynsham in the North East Somerset parliamentary constituency. Working with the local constituency Conservative Party in the run up to the 2014 European 
Parliament elections 1 the intervention included 6,123 registered voters.

Using the constituency office records on individual party support, we estimate the effect of the treatment on turnout overall, and on the turnout of supporters of different political parties. We find that the party's ground campaign, based on leaflets and door-to-door canvassing, did not increase turnout overall, but instead had a negative effect. Our analyses show that the campaign had a significantly more negative effect on supporters of rival parties than on supporters of the Conservative Party.

In this way, using campaign tactics that are frequently employed by Conservative constituency campaigns in the UK, the interventions worked to the party's advantage while failing to increase turnout at the aggregate. This study contributes to a more nuanced understanding of how ground campaigns can shape the composition of the electorate, while adding to the growing literature that points to some of the paradoxical consequences of campaign interventions for political participation (Enos, Fowler, and Vavreck 2014).

\section{How Can Campaign Contact Shape the Composition of}

\section{the Electorate?}

We are of course not the first to entertain the thought that partisan campaigns might result in differential turnout effects. As Holbrook and McClurg (2005, 695) argue, '[presidential] campaigns are most influential in shaping the partisan composition of the electorate rather than its overall size'. Moreover, as conclusions from two large field experiments conducted in collaboration with the French and Spanish Socialist Parties show, partisan ground campaigns routinely fail to lead to higher turnout in the aggregate, while at the same time increasing the vote share of the party that initiates the campaign intervention. While both Ramiro (2012, 23) and Pons (2014) explicitly mention that their intervention also targeted

\footnotetext{
${ }^{1}$ Constituency Conservative parties have responsibility for canvassing at all elections as well as for the parliamentary poll.
} 
supporters of rival parties, and they briefly entertain the thought that their intervention could have demobilized opponents, they opt for an explanation focused on persuasion rather than differential mobilization. As Pons (2014, 164) writes:

There are two possible interpretations of the results. The first is that the intervention mobilized left-wing nonvoters and cross-pressured and demobilized an equal number of (far) right-wing voters (Fiorina 1976).

It is not only field experiments that measure turnout at the aggregate level that show results consistent with differential mobilization. McNulty $(2005,53)$ found that Republicans that were contacted by a Democratic campaign were less likely to vote than the control group, albeit his sample size of Republican supporters was too small to detect significant effects. Stronger evidence is presented by Shi $(2015)$ who examines the effects of a campaign on same sex marriage that demobilized Republicans opposed to the issue. As Shi (2015) indicates, there is an important theoretical explanation for why campaigns can lead to demobilization among opponents. Political information that conflicts with political beliefs, attitudes or predispositions can create internal cross-pressure (Fiorina 1976, Hillygus and Shields 2008) and cognitive dissonance (Festinger 1957) among voters. This work on cross-pressure goes back to the classic studies of electoral politics (Lazarsfeld, Berelson, and Gaudet 1948, Berelson, Lazarsfeld, and McPhee 1954). One means of avoiding internal cross-pressure and cognitive dissonance is to abstain from making a choice (Hirschman 1970; Fiorina 1976). Campaigns that target supporters of rival parties might hence affect their turnout behavior via those psychological mechanisms. Exit might be a rational strategy for cross-pressured citizens if they want to relieve the cognitive dissonance caused by campaign interventions from candidates they oppose. Non-voting relieves the tension of voting for one's party when pressured not to do so, but it also prevents the tension that would be induced by being disloyal. For a campaign, it is beneficial if rival party supporters are demobilized. If they do not turn out, they do not vote for the other candidate. Even if voters followed an acceptance-rejection rule according to which they would be less likely to accept campaign messages from sources 
that did not match their partisan preferences (Zaller 1992), we would still expect differential mobilization effects between supporters of the party that initiates contact and supporters of rival parties (Foos and de Rooij 2016). The only worry for a campaign should be countermobilization that might occur when supporters of rival parties do the opposite of what a campaign would want them to do (Lupia and McCubbins 1998). While messages have been shown to 'backfire' in survey experiments (see, for instance, Nyhan and Reifler 2010), Arceneaux and Kolodny (2009) remain the only researchers to detect counter-mobilization effects as a results of randomized campaign interventions in the field. As a campaign strategy, demobilization might hence be particularly effective in challenging electoral environments where parties have trouble persuading supporters of other parties and where their own supporters are difficult to mobilize. In such cases, reducing turnout among opponents could be the most cost-effective way of tipping the partisan balance of an electorate in a party's favor.

\section{Are Standard, Light-Touch, Campaign Methods Effec-}

\section{tive?}

Other dimensions on which to understand the difference between partisan and non-partisan GOTV campaigns are mode and content. One of the best-known and most widely cited result from the non-partisan GOTV literature is that face-to-face contact (Green and Gerber 2008; Green, Aronow, and McGrath 2013), and heavy hitting interventions such as social pressure mailings (Gerber, Green, and Larimer 2008) are most effective at encouraging turnout.

But inherent differences between partisan and non-partisan campaigns may explain why messages might fail to reproduce some of the effect hierarchies that we have come to expect from non-partisan GOTV campaigns. In fact, while some partisan experiments replicate expected hierarchies of treatments, such as Arceneaux (2007) and Nickerson (2006), others do not (Shaw, Green, Gimpel, and Gerber 2012, Nickerson, Friedrichs, and King 2006, McNulty 2005; Adams and Smith 1980; Doherty and Adler 2014). Light-touch and even impersonal 
interventions might be effective in a partisan context because parties have a history of interacting with constituents. Establishing a social connection between the campaign and the voter through social interaction, which is seen as an important stimulus of turnout (Rogers, Fox, and Gerber 2012), would therefore be unnecessary. In these circumstances impersonal forms of communication might be sufficient to affect electoral behavior in repeated interactions. It is striking that when sent to voters who already interacted with a campaign, even impersonal light-touch methods such as text messages are effective at increasing turnout (Dale and Strauss 2009). Dale and Strauss (2009) argue that in this case text messages are effective because they are noticeable reminders.

If we combine the idea of repeated interactions using noticeable but light-touch interventions with the low-salience context of the European and local elections in the UK, we might expect that noticeable party reminders, no matter their form, will mostly influence voters who vote in General Elections, but who are at the verge of non-voting because of the low-salience of the second order election.

From this review, we would not expect a partisan campaign targeted towards the entire electorate to result in higher levels of turnout. Yet, even impersonal and light-touch modes of campaign interactions might be effective at shaping the composition of the electorate because campaigns relate to already existing social and political connections. Our differential mobilization hypothesis hence predicts that campaign interventions will lead party supporters (and to a lesser extent) unattached voters who are at the verge of non-voting to continue voting, while supporters of rival parties who are at the verge of non-voting in the low salience election might be pushed across the abstention threshold because they are cross-pressured by interacting with a party they dislike. 


\section{Study Design}

The site of the study was the small town in Keynsham in the west of England. The intervention was organised and delivered by the staff at the North East Somerset Conservative Party constituency offices in the three-week campaign period before the 2014 European Elections, which took place on 22 May. Keynsham is in the South West European Parliament constituency, which has six MEPs (before the 2014 election, which saw two Conservatives, two United Kingdom Independence Party (UKIP), one Green and one Labour MEP elected, three out of six MEPs were Conservative, one Liberal Democrat and two UKIP.). The study area was the wards of North and South Keynsham which are within walking distance of the constituency office. North Keynsham has 2,073 dwellings, and 5,035 individuals; South Keynsham has 2,253 dwellings and 5,019 individuals. All addresses with registered voters in the two wards were selected. Postal voters were removed on the grounds that they would have already cast their ballots by the time of the campaign. Hard-to-reach addresses, such as homes for the elderly, were removed where these were known. Randomization was blocked by ward: in Keynsham North, out of 1,660 households (3,253 individuals), 500 were randomly allocated to the canvass group and 500 to the leaflet group; in Keynsham South, out of 1,559 households (2,870 individuals), two randomly selected groups of 500 were also allocated to canvass and leaflet groups. This procedure created the final sample: 1,000 households to be canvassed; 1,000 to receive a leaflet; and the rest-1,219- to be left in the control group. An innovative aspect of this design is that it is able to isolate the treatment effect for canvassing even though all members of the canvass group also received a leaflet because the leaflet group was used as a control group from which an instrumental variable analysis could be conducted. In this way, it was possible to mimic the design of a campaign a local Conservative party would normally run whilst retaining the ability to make a causal inference. With households as the unit of randomization and contact, individual voters, from whom the outcome of voter turnout is measured, are clustered within these households. We take account of this feature of the design at the analysis stage. Since we intended to estimate mobiliza- 
tion effects by partisan group, it was important that the constituency office pre-recorded detailed data of the voting intentions of subjects based on previous canvassing campaigns.2 We divided our sample into three main categories: Conservative supporters, supporters of rival parties (Labour, Liberal Democrats, UKIP, Green Party etc.), and unattached voters (non-identifiers, non-voters and subjects with missing party identification data). We chose to rely on three broad partisan groups because canvasser data is a noisy measure of party support. While in the United Kingdom it is common practice for voters to volunteer their voting intentions to canvassers from rival parties, they sometimes choose to report vaguely, indicating for instance that they are 'Against Conservatives'. Moreover, the 'out-partisan' category has been validated using traditional phone interviews (Foos 2015, chapter 3). As the extensive robustness checks reported in the analysis section demonstrate, our findings are robust to a more fine-grained operationalization of party support.

The interview protocol was finalised after a pilot carried out on 15 and 16 April at 159 addresses, which were removed from the sample before randomisation. The protocol for the canvass group was a door knock at the intervention group addresses where the canvasser sought to talk to a person on the electoral register. The canvasser left a leaflet - either to give to the respondent or put through the door if there was no response. The canvasser recorded whether a contact had taken place and even a brief opening of the door counted. The message was a standard question about whether the respondent was intending to vote Conservative and an encouragement to vote for the party. The script ran as follows: 'Good morning/afternoon/evening. I am from the Conservative Party. (Hand over leaflet). I am just checking to see if you are going to vote Conservative in the upcoming European elections.' If response was yes/no and the person is the only elector in the household, the canvasser went on to say: 'I am very glad/sorry to hear about that. We look forward to getting your

\footnotetext{
${ }^{2}$ Canvassers make written records of the party the respondent indicates they are going support in the forthcoming poll and which are updated at each election and are available for around $58 \%$ of registered voters. These are recorded in the following way: $\mathrm{B}=\mathrm{BNP}, \mathrm{G}=$ Green, $\mathrm{I}=$ Independent, $\mathrm{M}=$ possible Lib Dem, $\mathrm{T}=$ possible Labour, $\mathrm{U}=$ Undecided, $\mathrm{C}=$ Conservative, $\mathrm{P}=$ possibly Conservative, $\mathrm{S}=$ Labour (socialist), $\mathrm{L}=\mathrm{Lib}$ Dem, $\mathrm{K}=\mathrm{UKIP}, \mathrm{W}=$ Won't vote (various reasons including religious beliefs) and $\mathrm{A}=$ Against Conservative.
} 
vote/I'm sorry we won't be getting your vote but thank you anyway.' If the response was yes/no and there were other electors in the household the script was: 'I am very glad/sorry to hear about that. And which way are other members of the household voting? Thank you for your help.' There was no script beyond this point. The canvasser did not give any indication that the respondent should turn out in general or that turnout was a good thing, eschewing the classic GOTV techniques such as emphasising civic duty. In some cases conversations carried on about matters in local politics or anything else of interest to the voter as there was an emphasis on keeping the contact natural and informal. In practice, the intervention was usually short, lasting about two minutes..$^{3}$ The canvasser recorded which person from the household he or she had spoken to and whether they intended to vote Conservative or not, or noted which other party they intend to vote for or whether not intending to vote.

The constituency office produced lists of addresses from the canvass treatment and then created walkways. Canvassing was carried out during the three weeks before the election date. There were twelve canvassers in total, including the local MP, but the local councillors carried out most of the door knocks. $4^{4}$ Canvassers attempted to treat subjects in 1,000 households and were successful at contacting 406 households including a total of 808 subjects. This represents $41 \%$ of households or $43 \%$ of subjects that were cluster-randomly assigned to the canvassing treatment. The group of compliers includes 252 Conservative voters, 204 supporters of rival parties and 354 subjects who were listed as unattached. Leaflets delivered via mail were the same as those received by the canvass group (see Figure 1). This printed document showed pictures of three local politicians (not the European candidates, but the local MP and two councillors), and invited the respondent to vote Conservative. There was no explicit GOTV message. The control households were left alone.

\footnotetext{
${ }^{3}$ One of the researchers visited the constituency office on 20 May and accompanied one of the canvassers, a locally elected representative, on the campaign.

${ }^{4}$ This raises the possibility that canvassers differ in their effect on voters. However, the specific person was not randomly assigned, so any analysis would be observational.
} 
Figure 1: Leaftet given to all treatment households in Keynham North and Keynham South.

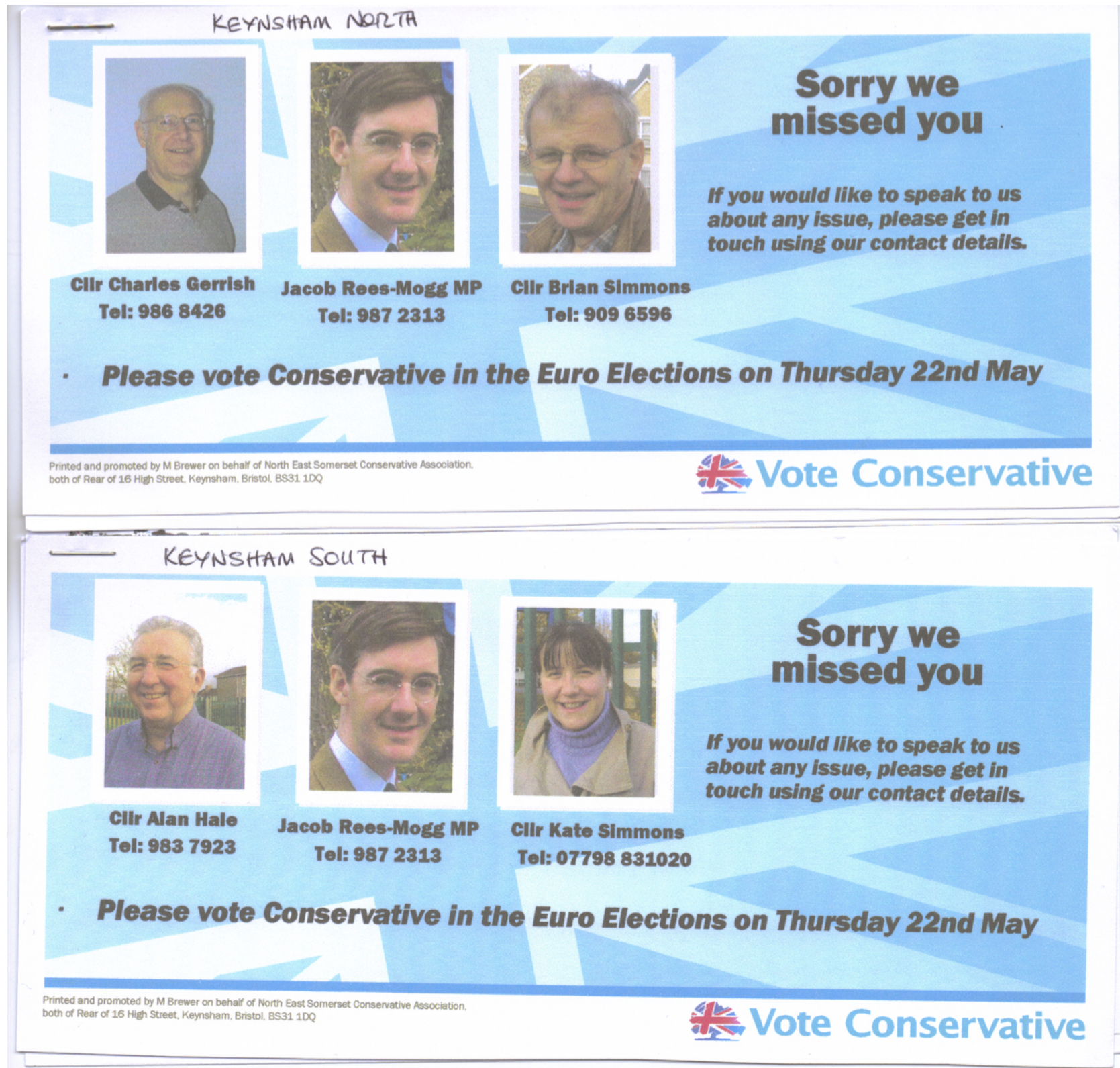


Data were recorded in the constituency office. Before random assignment, the party made available data about party support available to us, which it had recorded in previous canvassing efforts. In order to perform a randomization check, we also obtained pre-treatment data on (verified) turnout in the 2010 General Election, and the sex of the voter. In order to check if, taken together, our pre-treatment covariates significantly predict treatment assignment, we regress assignment to one of the two treatment groups (1) or to control (0) on all available pre-treatment covariates (2010 turnout, gender and pre-treatment party support), and conduct a joint f-test. The p-value of .16 indicates that covariate differences between treatment and control groups are not statistically significant (Table A1 in the Supporting Information provides detailed information on covariate balance between treatment and control groups) $]^{5}$ After the election in May 2014, turnout data were requested from the local authority and matched to the dataset. Data were prepared by the office and were sent to the researchers.

\section{Results}

Table 1 and Tables A3 and A4 in the Supporting Information present the results from eight logistic regression models of the combined ground campaign, as well as the two campaign interventions separately, on turnout. In all models, standard error estimates are clustered by household to account for assignment to treatment and control groups at the household

\footnotetext{
${ }^{5}$ In addition, we use randomisation inference to test whether we can reject the sharp null hypothesis that any existing imbalance in pre-treatment covariates between the experimental groups could have occurred due to sampling variability alone. To perform the randomization-inference-based balance check, we first extract the log likelihood statistic resulting from a multinomial logistic regression of treatment assignment on all available pre-treatment covariates. We then compare the extracted log likelihood to the mean of all $\log$ likelihoods that we obtain after simulating cluster random assignment within each of the two experimental blocks 5,000 times. The resulting p-value of .79 indicates that we cannot reject the sharp null hypothesis that pre-treatment covariates are not systematically related to treatment assignment. We are therefore confident about the balanced nature of treatment and control groups. Moreover, we perform a further balance check using the same procedure, but including interactions between pre-treatment party-support, turnout and gender. Again, we find no evidence that treatment assignment within partisan strata was systematically related to previous turnout or gender. Figure A1 in the Supporting Information shows where the log likelihood resulting from a multinomial logistic regression of treatment assignment on pre-treatment covariates falls within the sampling distribution of all test statistics obtained after re-assigning households to treatment and control under the sharp null hypothesis.
} 
level. The coding of the party identification variable differs in Table 1 and Tables A3 and A4. While Table 1 shows treatment effects conditional on the three larger partisan sub-groups outlined in the research design section, Tables A3 and A4 include a detailed breakdown of support for rival parties and a more finely-grained categorization of unattached voters, demonstrating that our results are not driven by our operationalization of pre-treatment partisan subgroups.

Model 1 in Table 1 shows the overall results of the Conservative canvassing and leafletting campaign compared to the untreated control group. It is clear that, overall, the campaign interventions, if at all, had a negative effect on turnout, significant at the .10 level. Models 2,3 , and 4 include interactions with pre-treatment party support dummies testing our differential mobilization hypothesis that the campaign increased turnout among supporters of the Conservative Party more than turnout among supporters of rival parties such as Labour. Model 3 adds the pre-treatment covariates gender and validated turnout in the 2010 General Election, while Model 4 also adds interactions between treatment assignment and pre-treatment covariates, testing whether the conditional treatment effects by partisanship are driven by compositional differences within partisan groups. Models 5 to 8 replicate the aforementioned steps, breaking the ground campaign down into its constituent parts, namely whether a household was sent a leaflet only, or if the household was also assigned to personal contact with a Conservative Party canvasser. Table 1 Models 2 and 6 clearly demonstrate that campaign interventions had a different (more negative) effect on the turnout of rival party supporters and unattached voters than on the turnout of Conservative Party supporters. The differential effects are statistically significant with $\mathrm{p}<.05$.

Models 3 and 4 show that the differential effect for supporters of rival parties is robust to the inclusion of pre-treatment covariates as well as to the inclusion of interactions of pre-treatment covariates and the treatments, suggesting that the key result is not a function of observed compositional differences between partisan subgroups. Moreover, the interactions of the treatments with unattached subjects show that the differential effect uncovered in 


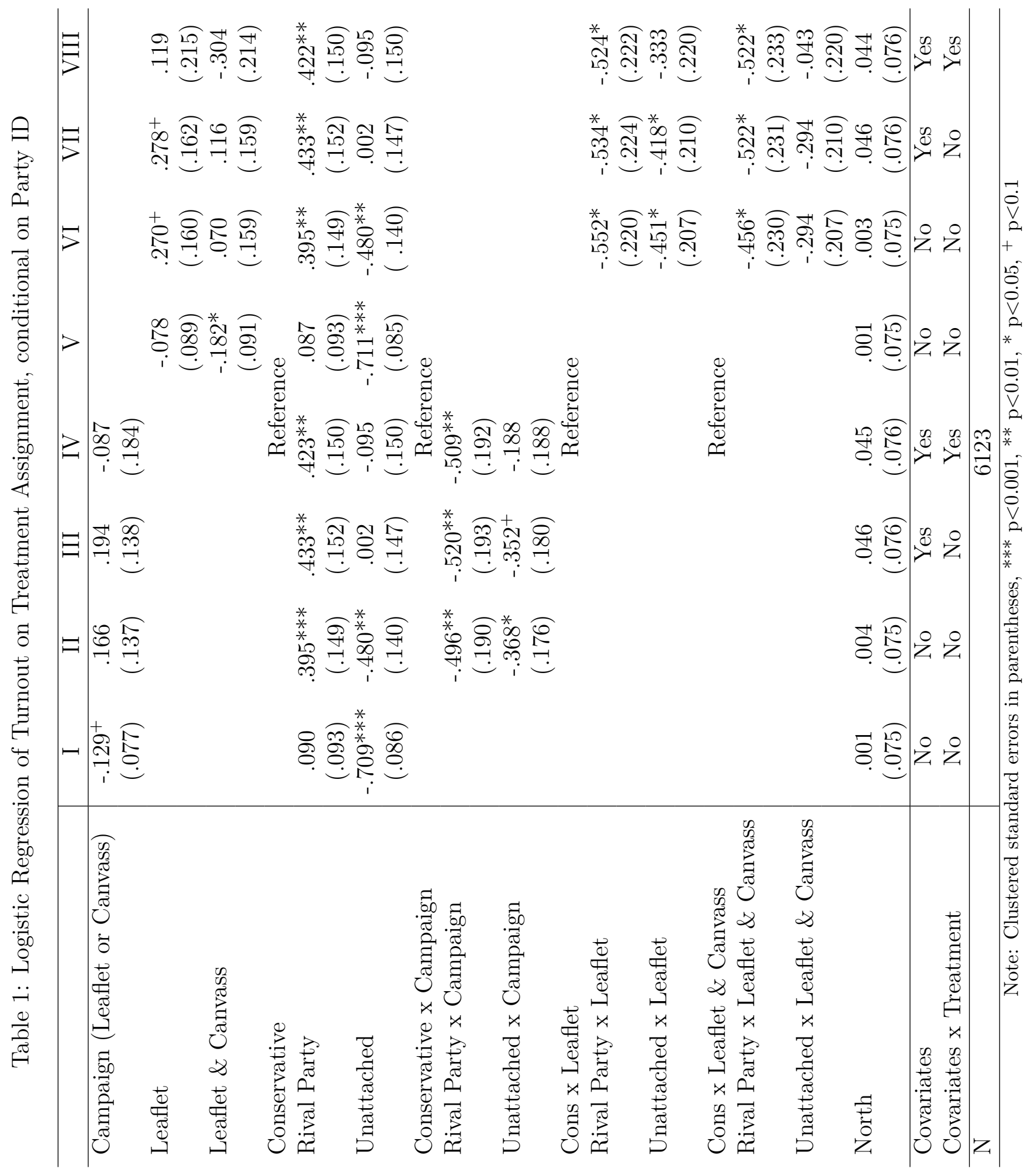


Models 2 and 6 is, in fact, a function of observable compositional differences with unattached voters, ex-ante, less likely to vote than party identifiers and the treatment being more effective with higher propensity voters. If our theory that rival party supporters are put off voting by contact from a rival campaign because of their partisanship is correct, then that is exactly what we should observe: robust differential effects of the treatment between Conservative supporters and supporters of rival parties, and differential effects between Conservative supporters and unattached voters due to compositional differences related to pre-treatment turnout propensity.

Tables A3 and A4 displays a further robustness check, dividing the three partisan subgroups using all available information on partisanship from the Conservative campaign office. The significant negative interaction effects displayed in Table A4 between both treatments and the Labour Party dummy show that the negative effect for rival party supporters is driven by supporters of the largest rival party, the Labour Party: treatments had a significantly more negative effect on Labour supporters than on Conservative supporters.

Moreover, Table A3 demonstrates that the negative effect for unattached voters is mainly driven by subjects with missing data on the party identification variable, and not by selfdeclared non-voters and non-identifiers, who turn out more when treated.

Figure 2 plots the marginal changes in predicted turnout probabilities derived from Table 1 and Table A4 models 6 and 8 (adjusted for all available pre-treatment covariates and the interactions between pre-treatment covariates and assignment to campaign contact). The predicted ITTs are estimated while holding covariates at their mean. Figure 2 clearly shows that the differences in treatment effects between Conservative supporters and rival party supporters is statistically significant and amounts to 12 percentage points (unadjusted) or 11 percentage points (covariate-adjusted).

We also correct for multiple comparisons by applying the Benjamini and Hochberg correction, which controls the False Discovery Rate (FDR). We follow the method outlined by Coppock (2015). Since analysis includes pre-treatment covariates displayed in Table 1 Model 
Figure 2: ITT Effects of Canvassing on Turnout, conditional on Party ID
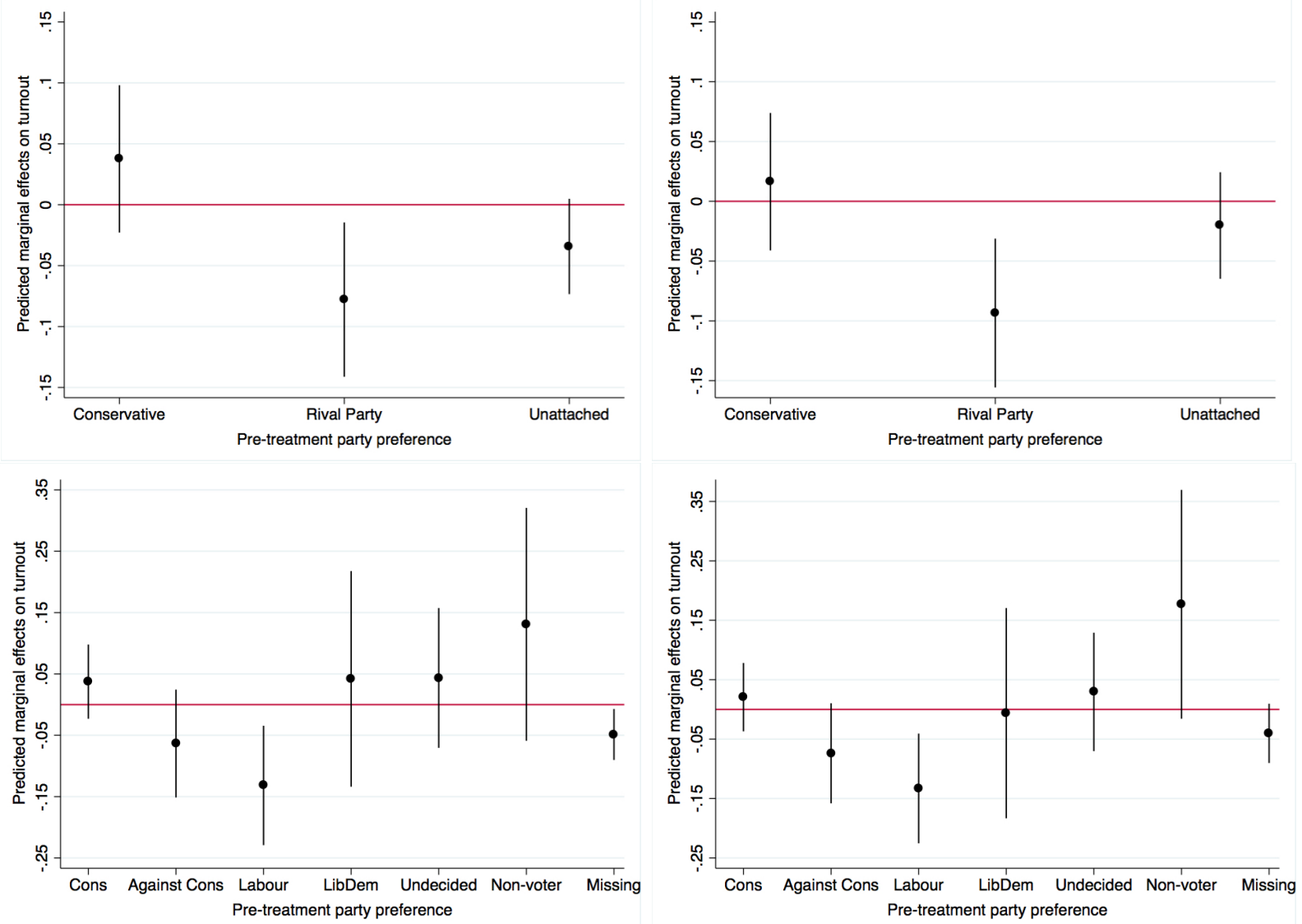

Note: Bars denote 95\% Confidence Intervals.

First row: three-group specification, Second row: seven-group specification

First column: unadjusted, Second column: covariate-adjusted 
4, we performed subgroup analysis for each of the three partisan subgroups, we begin by ordering the three p-values from the smallest to the largest. Then we look for the largest p-value that satisfies: $p_{k}<=(k / m) * \alpha$, where $\mathrm{k}$ is the p-values index, $\mathrm{m}$ is the number of tests, and $\alpha$ is .10. According to Coppock (2015), this p-value and all smaller p-values remain statistically significant at the .10 level. The corrected p-values in Table 2 show that the interaction between the campaign and the rival partisan group (the key finding of this paper) remains significant at the .05 level with $\mathrm{p}=.024$.

Since in 1 Model 8 we performed two hypothesis tests for each of the three partisan subgroups, we again order the six p-values from the smallest to the largest, and locate the largest p-value that satisfies: $p_{k}<=(k / m) * \alpha$, where $\mathrm{k}$ is the $\mathrm{p}$-values index, $\mathrm{m}$ is the number of tests, and $\alpha$ is .10. The corrected p-values in Table 2 show that, if we decompose the campaign treatment, the interactions between the leaflet and the rival partisan group, and the canvassing and the rival partisan group, both remain significant, albeit only at the .10 level, with $\mathrm{p}=.075$.

Table 2: Benjamini-Hochberg correction for FDR

\begin{tabular}{l|cc}
\hline & Raw p-values & Adjusted p-values \\
\hline & \multicolumn{2}{|c}{ Table 1 Model 4} \\
\hline Cons x Campaign & .635 & .635 \\
Rival Party x Campaign & $.008^{* *}$ & $.024^{*}$ \\
Unattached x Campaign & .316 & .474 \\
\hline & \multicolumn{2}{|c}{ Table 1 Model 8} \\
\hline Cons x Leaflet & .155 & .232 \\
Cons x Canvass \& Canvass & .582 & .698 \\
Rival Party x Leaflet & $.025^{*}$ & $.075^{+}$ \\
Rival Party x Leaflet \& Canvass & $.018^{*}$ & $.075^{+}$ \\
Unattached x Leaflet & .846 & .846 \\
Unattached x Leaflet \& Canvass & .130 & .232 \\
\hline \multicolumn{2}{c}{ Note: Two-tailed tests, ${ }^{* * *} \mathrm{p}<0.001,{ }^{* *} \mathrm{p}<0.01,{ }^{*} \mathrm{p}<0.05,{ }^{+} \mathrm{p}<0.1}$.
\end{tabular}

Table 3 shows the results of a multinomial logistic regression of difference in turnout behaviour between the 2010 General Election and 2014 European Elections as a function of treatment assignment, pre-treatment party support and the interaction between treatment 
Table 3: Multinomial Logistic Regression of Change in Turnout between 2010 and 2014 on Treatment Assignment, conditional on Party ID

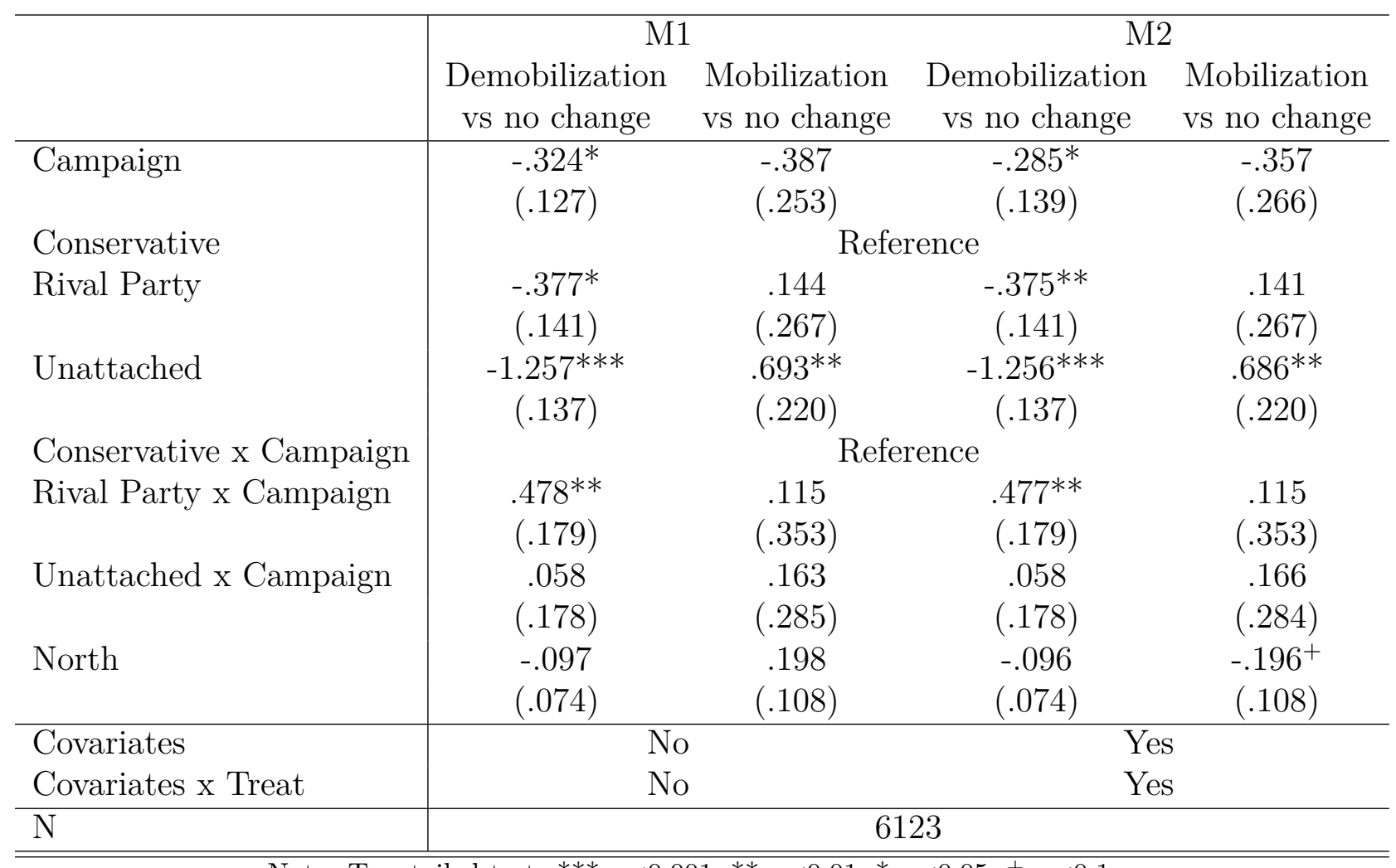

Note: Two-tailed tests ${ }^{* * *} \mathrm{p}<0.001,{ }^{* *} \mathrm{p}<0.01,{ }^{*} \mathrm{p}<0.05,{ }^{+} \mathrm{p}<0.1$

assignment and pre-treatment party-support..$^{6}$ Model 2 also includes the pre-treatment covariate, sex, and interactions between treatment assignment and gender. The dependent variable is coded -1 if the subject turned out in the 2010 General Election and abstained in the 2014 European election, 0 if the subject abstained in both elections or turned out in both elections, and 1 if the subject abstained in the 2010 General Election but turned out in the 2014 European election.

From the low salience electoral context and light-touch nature of both campaign interventions, we expect that the campaign should change the electoral behaviour of General Election voters either by activating the existing connection between party and voter, and thus preventing them from abstaining in the lower salience, European elections, or by pushing them

\footnotetext{
${ }^{6}$ Since turnout as a whole, and conditional on pre-treatment party support does not differ significantly as a function of being canvassed compared to receiving the leaflet only (see Table A5 in the Supporting Information), we restrict our analysis to the effect of campaign contact compared to no campaign contact.
} 
across the abstention threshold (in the case of rival party supporters).

This change is exactly what we observe with Conservative supporters. The main treatment effects in Table 3 show that the campaign reduced second order election abstention among Conservative voters who voted in the 2010 General Election. In contrast, the statistically significant interaction effect with supporters of rival parties shows that those subjects, if they voted in 2010, were significantly less likely to be prevented from abstaining than subjects who supported the Conservative Party. Figure 3 plots the marginal changes in predicted probabilities for each type of voter derived from Table 3, Models 1 (displayed in column 1) and 2 (displayed in column 2). The first row shows how the treatment affected low salience abstention compared to continuing with General Election turnout behaviour. The second row plots how the treatment affected continuity between low and high salience turnout behaviour, and the third row displays mobilization effects among General Election non-voters. The marginal effects plots show that Conservatives are around 8 percentage points more likely to stick with their General Election turnout behaviour when assigned to contact either by leaflet or door-to-door, and those who stick are 7 percentage points more likely to keep on voting. On the other hand, supporters of rival parties who voted in the 2010 General Election are 3 percentage points more likely to abstain from voting in the European elections (n/s) when assigned to treatment as compared to control, but also 2 percentage points less likely to start voting in the Europeans (n/s), which means that the significant and negative main effect on turnout among rival party supporters observed in Figure 2 may be a composite of higher abstention among General Election voters and lower turnout among 2010 General Election non-voters (e.g. subjects that were too young to vote in 2010).

\section{Discussion and Conclusion}

Large-scale partisan campaign experiments that randomize contact at the aggregate level often report positive effects on parties' vote shares while failing to detect effects on aggregate 
Figure 3: Change in Turnout from General Election 2010 to European Election 2014 as Function of Treatment Assignment, conditional on Party ID
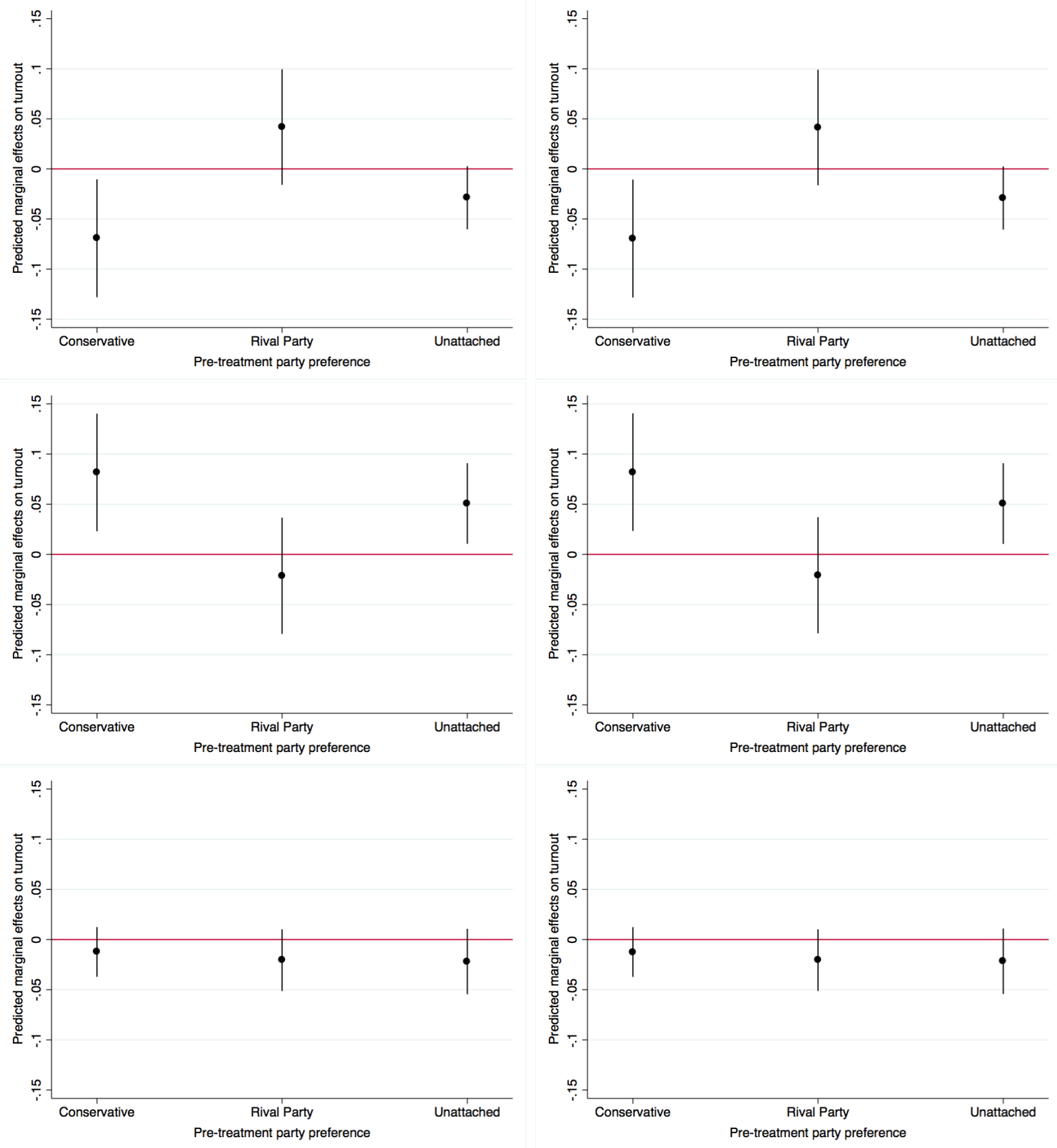

Row 1: Voter 2010 -> Non-voter 2014

Row 2: No change 2010-2014

Row 3: Non-voter 2010 -> Voter 2014

Column 1: unadjusted, Column2: covariate-adjusted

Note: Bars denote 95\% Confidence Intervals. 
turnout (Ramiro, Morales, and Jiménez-Buedo 2012, Pons 2014, Pons and Liegey 2016. Kendall, Nannicini, and Trebbi 2014). But are these effects entirely due to persuasion as the literature suggests? By developing a theory of differential mobilization and testing it on individual-level data collected from a randomized field experiment conducted in collaboration with the North East Somerset Conservative Party, we show that campaigns can affect the partisan composition of the electorate in favor of the party that initiates contact, while leaving aggregate turnout unchanged.

Null results, or even negative results, on turnout should not be surprising given that partisan campaigns have different strategic objectives than civic campaigns. As Gerber (2004) points out, winning an election may sometimes involve reducing turnout among opponents. This outcome is particularly likely in multi-party systems where supporters of the party that initiates contact only make up a fraction of voters that are targeted by a campaign. The aim of this research was to test the differential impact of two common campaign methods on supporters of different parties. Differential partisan effects of door-to-door canvassing and leafleting on turnout have so far either been ignored because most partisan campaign experiments are based on samples that exclude rival party supporters (e.g. Nickerson, Friedrichs, and King 2006) or because they lacked detailed information on pre-treatment party support (e.g. Pons 2014). We show that parties might be skilled at mobilizing their core voters to turn out while deterring voters of rival parties by using the same campaign intervention. Taking the case of one major party's campaign in the 2014 European and local elections in an English parliamentary constituency, the research examined the differential turnout hypothesis, confirming that both the campaign overall, but also each intervention, leafleting and canvassing, separately affected the composition of the electorate favorably from the standpoint of the Conservative Party. Our results suggest that differential mobilization may be an important feature of partisan campaigning and should be explored further. While the causal mechanism leading to demobilization effects among opponents could be cognitive dissonance or cross-pressure induced through contact with a rival campaign, it may also be 
the case that campaign contact from an opposing party causes frustration and discontent with politics in general.

It should also be borne in mind that in European and local elections turnout is relatively low by UK (but not by US) national election standards. In a General Election when turnout is higher and all parties are attempting to contact voters, and when voters consider the election to be more important, incentive for party loyalists to turnout in favor of their preferred party may be stronger. It therefore remains to be tested whether differential mobilization is generalizable to high salience elections. Of course, in the comparative context, where electoral systems and party competition differ, differential mobilization may also vary in its importance.

For scholars of GOTV and partisan campaigns, it might not be surprising that the script routinely delivered to voters at the doorstep by Conservative Party volunteers in North East Somerset was no more effective at affecting turnout than a simple campaign leaflet. The standard canvassing script used by the Conservative Party contained no specific behavioral cues that have been shown to make personal appeals more effective at getting out the vote Green and Gerber 2008, Nickerson 2007). This experiment is therefore a reminder that voter contact statistics, as published routinely by political parties in the UK and elsewhere in the run-up to an election, are not necessarily a good indication of the effectiveness of a party's ground operation. In this way, the findings, if replicated, might qualify other studies of partisan mobilization that have stressed the general importance of face-to-face interaction. Used heavily by Conservative campaigns in marginal seats during the 2015 UK General Elections, the effectiveness of the campaign leaflet in North East Somerset, a ConservativeLabour marginal, might help to explain some of the party's unexpected victories despite Labour's advantage in making door-to-door contact.

Our results show that contacting registered voters via leaflet and door-to-door canvassing are both effective at changing the composition of the electorate in a low salience election. This paper provides a novel explanation for the surprising empirical regularity that partisan 
campaigns often fail to increase turnout both at the individual and the aggregate level. 


\section{References}

Adams, William C., and Dennis J. Smith. 1980. "Effects of Telephone Canvassing on Turnout and Preferences: A Field Experiment." Public Opinion Quarterly 44 (3): 389-395.

Arceneaux, Kevin. 2007. "I'm Asking for Your Support: The Effects of Personally Delivered Campaign Messages on Voting Decisions and Opinion Formation." Quarterly Journal of Political Science 1: 43-65.

Arceneaux, Kevin, and Robin Kolodny. 2009. "Educating the least informed: Group endorsements in a grassroots campaign." American Journal of Political Science 53 (4): 755-770.

Bailey, Michael A., Daniel J. Hopkins, and Todd Rogers. 2016. "Unresponsive and Unpersuaded: The Unintended Consequences of a Voter Persuasion Effort." Political Behavior 38 (3): $713-746$.

Barton, Jared, Marco Castillo, and Ragan Petrie. 2014. "What persuades voters? A field experiment on political campaigning." The Economic Journal 124 (574): 293-326.

Berelson, Bernard, Paul Felix Lazarsfeld, and William N McPhee. 1954. Voting: a study of opinion formation in a presidential campaign. Midway reprint midway reprint ed ed. Chicago: University of Chicago Press.

Coppock, Alexander. 2015. 12 Things you need to know about multiple comparisons. EGAP: http://egap.org/resources/guides/10-things-you-need-to-know-aboutmultiple-comparisons/.

Dale, Allison, and Aaron Strauss. 2009. "Don’t Forget to Vote: Text Message Reminders as a Mobilization Tool." American Journal of Political Science 53 (4): 787-804.

Doherty, David, and E. Scott Adler. 2014. "The Persuasive Effects of Partisan Campaign Mailers." Political Research Quarterly 59: 203-210. 
Enos, Ryan D, Anthony Fowler, and Lynn Vavreck. 2014. "Increasing Inequality: The Effect of GOTV Mobilization on the Composition of the Electorate." The Journal of Politics 76 (1): 273-288.

Festinger, Leon. 1957. A Theory of Cognitive Dissonance. Evanston, Ill.: Row, Peterson.

Fiorina, Morris P. 1976. "The Voting Decision: Instrumental and Expressive Aspects." The Journal of Politics 38: 390-413.

Foos, Florian. 2015. Bringing the Party Back in: Mobilization and Persuasion in Constituency Election Campaigns. PhD Thesis: University of Oxford.

Foos, Florian, and Eline A. de Rooij. 2016. "The Role of Partisan Cues in Voter Mobilization Campaigns: Evidence from a Randomized Field Experiment." Working Paper .

Gerber, Alan. 2004. "Does Campaign Spending Work?: Field Experiments Provide Evidence and Suggest New Theory." American Behavioral Scientist 47 (5): 541-574.

Gerber, Alan, Donald Green, and Christopher Larimer. 2008. "Social Pressure and Voter Turnout: Evidence from a Large-Scale Field Experiment." American Political Science Review 102 (01): 33-48.

Green, Donald P. 2004. "Results from a Partisan Phone and Canvassing Mobilization Campaign in Pennsylvania Primary Election." Institution for Social and Policy Studies, Yale University, http://gotv.research.yale.edu/.

Green, Donald P., and Alan S Gerber. 2008. Get Out the Vote: How to Increase Voter Turnout. 2nd ed ed. Washington, D.C.: Brookings Institution Press.

Green, Donald P., Peter M. Aronow, and Mary C. McGrath. 2013. "Field Experiments and the Study of Voter Turnout." Journal of Elections, Public Opinion $\&$ Parties 23 (1): 27-48. 
Hillygus, Sunshine D., and Todd G. Shields. 2008. The Persuadable Voter: Wedge Issues in Presidential Campaigns. Princeton: Princeton University Press.

Hirschman, Albert O. 1970. Exit, Voice, and Loyalty: Responses to Decline in Firms, Organizations, and States. Cambridge, MA: Harvard University Press.

Holbrook, Thomas M., and Scott D. McClurg. 2005. "The Mobilization of Core Supporters: Campaigns, Turnout and Electoral Composition in United States Presidential Elections." American Journal of Political Science 49 (4): 689-703.

Huber, Gregory A., and Kevin Arceneaux. 2007. "Identifying the Persuasive Effects of Presidential Advertising." American Journal of Political Science 51 (4): 961-81.

Kendall, Chad, Tomasso Nannicini, and Francesco Trebbi. 2014. "How Do Voters Respond to Information? Evidence from a Randomized Campaign." The American Economic Review 105 (1): 322-353.

Lazarsfeld, Paul Felix, Bernard Berelson, and Hazel Gaudet. 1948. The people's choice: how the voter makes up his mind in a presidential campaign. New York: Columbia Univ. Press.

Lupia, Arthur, and Mathew D. McCubbins. 1998. The Democratic Dilemma: Can Citizens Learn What They Need to Know? Cambridge: Cambridge University Press.

McNulty, John E. 2005. "Phone-Based GOTV - What's on the Line? Field Experiments with Varied Partisan Components, 2002-2003." The Science of Voter Mobilization. Special Editors: Donald P. Green and Alan S. Gerber. The Annals of the American Academy of Political and Social Science. 601: 41-65.

Nickerson, David W. 2005. "Partisan Mobilization Using Volunteer Phone Banks and Door Hangers." The Annals of the American Academy of Political and Social Science 601 (1): 10-27. 
Nickerson, David W. 2006. "Forget Me Not? The Importance of Timing in Voter Mobilization." Paper presented at the annual meeting of the American Political Science Association.

Nickerson, David W. 2007. "Quality is Job One: Volunteer and Professional Phone Calls." American Journal of Political Science 51 (2): 269-282.

Nickerson, David W., Ryan D. Friedrichs, and David C. King. 2006. "Partisan Mobilization Campaigns in the Field: Results from a Statewide Turnout Experiment in Michigan." Political Research Quarterly 59 (1): 85-97.

Nyhan, Brendan, and Jason Reifler. 2010. "When Corrections Fail: The Persistence of Political Misperceptions." Political Behavior 32 (303-330).

Pons, Vincent. 2014. The Determinants of Political Behavior : Evidence from Three Randomized Field Experiments. Massachusetts Institute of Technology: PhD Thesis.

Pons, Vincent. 2016. "Will a Five-Minute Discussion Change Your Mind?" Harvard Business School Working Paper 16-079.

Pons, Vincent, and Guillaume Liegey. 2016. "Increasing the Electoral Participation of Immigrants. Experimental Evidence from France." Harard Business School Working Paper $16-094$.

Ramiro, Luis, Laura Morales, and María Jiménez-Buedo. 2012. "The Effects of Party Mobilization on Electoral Results. An Experimental Study of the 2011 Spanish Local Elections." Paper prepared for the IPSA conference, July 2012.

Rogers, Todd, Craig R. Fox, and Alan S. Gerber. 2012. "Rethinking Why People Vote: Voting as Dynamic Social Expression." In The Behavioral Foundations of Policy, ed. Eldar Shafir. Princeton University Press.

Shaw, Daron R, Donald P. Green, James G. Gimpel, and Alan S. Gerber. 2012. "Do Robotic 
Calls From Credible Sources Influence Voter Turnout or Vote Choice? Evidence From a Randomized Field Experiment." Journal of Political Marketing 11: 231-245.

Shi, Ying. 2015. "Cross-cutting Messages and Voter Turnout: Evidence from a Same-Sex Marriage Amendment." Political Communication . forthcoming: 10.1080/10584609.2015.1076091.

Zaller, John. 1992. The Nature and Origins of Mass Opinion. Cambridge University Press. 


\title{
Online Supporting Information
}

\author{
Parties Are No Civic Charities: \\ Voter Contact and the Changing Partisan Composition \\ of the Electorate
}

\author{
Florian Foos* $\quad$ Peter John ${ }^{\dagger}$ \\ Political Science Research and Methods
}

October 2016

Replication Materials: The data, code, and any additional materials required to replicate all analyses in this article are available on the Political Science Research and

Methods Dataverse within the Harvard Dataverse Network, at:

http://dx.doi.org/10.7910/DVN/EWISS3

*Department of Political Science, University of Zurich, Affolternstrasse 56, 8050 Zurich, Switzerland, foos@ipz.uzh.ch

${ }^{\dagger}$ Department of Political Science, University College London, The Rubin Building, 29/31 Tavistock Square, London WC1H 9QU, United Kingdom, peter.john@ucl.ac.uk 


\section{Supporting Information}

Table A1: Covariate balance, by experimental group \& partisanship

\begin{tabular}{l|ccc}
\hline & Canvass & Leaflet & Control \\
\hline & \multicolumn{3}{|c}{ North } \\
\hline Conservative & 30.3 & 28.9 & 30.3 \\
Against Con & 8.8 & 8.7 & 10.0 \\
Labour & 8.0 & 11.7 & 11.5 \\
LibDem & 4.1 & 1.8 & 3.1 \\
Undecided & 7.1 & 6.6 & 9.0 \\
Non-voter & 1.7 & 2.2 & 1.8 \\
Missing & 39.9 & 40.0 & 34.3 \\
Female & 51.3 & 50.9 & 50.4 \\
Unknown & 0.9 & 1.3 & 0.6 \\
Turnout 2010 & 43.1 & 42.8 & 46.4 \\
\hline N & \multicolumn{3}{|c}{3253} \\
\hline & South \\
\hline Conservative & 27.4 & 22.1 & 21.3 \\
Against Con & 13.8 & 16.7 & 13.0 \\
Labour & 8.4 & 9.1 & 10.4 \\
LibDem & 2.2 & 3.0 & 2.8 \\
Undecided & 2.1 & 2.3 & 3.2 \\
Non-voter & 0.9 & 0.8 & 1.1 \\
Missing & 45.3 & 46.0 & 48.3 \\
Female & 54.0 & 53.8 & 51.4 \\
Unknown & 0.9 & 1.2 & 1.4 \\
Turnout 2010 & 45.3 & 46.7 & 48.5 \\
\hline N & & 2870 \\
\hline
\end{tabular}




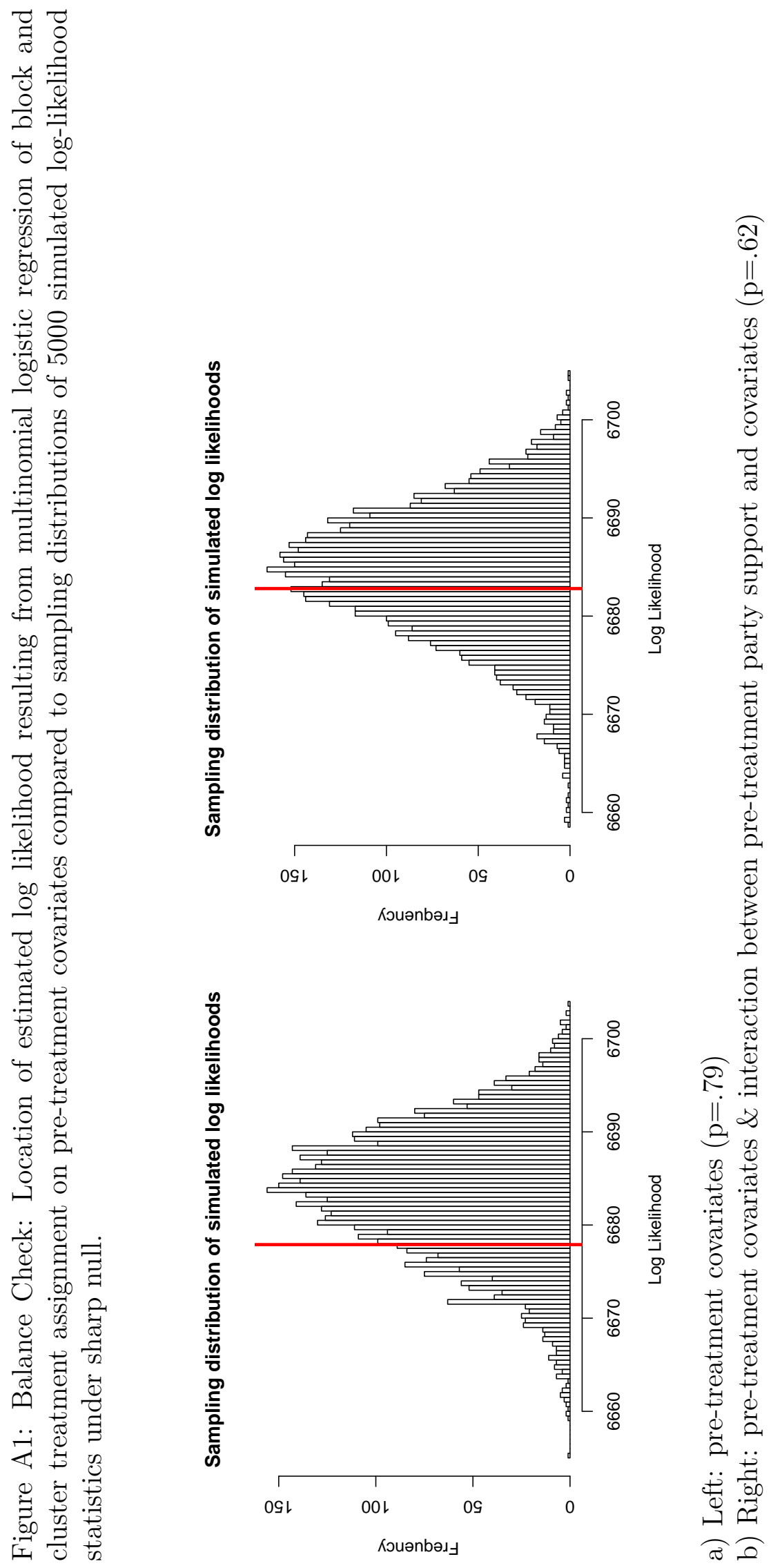


Table A2: Turnout rates by experimental block and pre-treatment party support

\begin{tabular}{l|cccc}
\hline & Canvass & Leaflet & Control & Combined \\
\hline & \multicolumn{4}{|c}{ North } \\
\hline Combined & 28.2 & 29.1 & 30.1 & 29.2 \\
& $(974)$ & $(980)$ & $(1299)$ & $(3253)$ \\
\hline Conservative & 34.9 & 36.7 & 34.8 & 35.4 \\
Against Cons & $(295)$ & $(283)$ & $(394)$ & $(972)$ \\
& 27.9 & 38.8 & 37.7 & 35.2 \\
Labour & $(86)$ & $(85)$ & $(130)$ & $(301)$ \\
& 28.2 & 29.6 & 38.0 & 32.9 \\
LibDem & $(78)$ & $(115)$ & $(150)$ & $(343)$ \\
& 45.0 & 55.6 & 50.0 & 49.0 \\
Undecided & $(40)$ & $(18)$ & $(40)$ & $(98)$ \\
& 29.0 & 27.7 & 21.4 & 25.1 \\
Non-voter & $(69)$ & $(65)$ & $(117)$ & $(251)$ \\
& 29.4 & 27.3 & 13.0 & 22.6 \\
Missing & $(17)$ & $(22)$ & $(23)$ & $(62)$ \\
& 21.3 & 20.4 & 22.5 & 21.5 \\
Canvassing contact rate & $(389)$ & $(392)$ & $(445)$ & $(1226)$ \\
\hline \hline & 41.4 & 0.0 & 0.0 & 12.4 \\
\hline Combined & \multicolumn{3}{|c}{ South } \\
& 25.6 & 28.9 & 31.4 & 28.8 \\
Conservative & $(909)$ & $(923)$ & $(1038)$ & $(2870)$ \\
\hline \multirow{4}{*}{ Against Cons } & 34.1 & 42.6 & 29.9 & 35.3 \\
& $(249)$ & $(204)$ & $(221)$ & $(674)$ \\
Labour & 43.2 & 31.8 & 45.9 & 39.9 \\
& $(125)$ & $(154)$ & $(135)$ & $(414)$ \\
LibDem & 25.0 & 34.5 & 49.1 & 37.7 \\
Undecided & $(76)$ & $(84)$ & $(108)$ & $(268)$ \\
Non-voter & 20.0 & 60.7 & 31.0 & 39.0 \\
Missing & $(20)$ & $(28)$ & $(29)$ & $(77)$ \\
& 15.8 & 28.6 & 27.3 & 24.7 \\
Canvassing contact rate & 44.6 & 0.2 & 0.0 & $(73)$ \\
& $(19)$ & $(21)$ & $(33)$ & 23.1 \\
& 37.5 & 14.3 & 18.2 & $(26)$ \\
& $(8)$ & $(7)$ & $(11)$ & 20.0 \\
& 15.8 & 18.4 & 25.0 & $(4.2$ \\
\hline
\end{tabular}

Note: Number of observations in parentheses. 
Table A3: Logistic regression of turnout on treatment assignment, conditional on Party ID

\begin{tabular}{|c|c|c|c|c|}
\hline & I & II & III & IV \\
\hline Campaign & $\begin{array}{l}-.127^{+} \\
(.077)\end{array}$ & $\begin{array}{l}.165 \\
(.137)\end{array}$ & $\begin{array}{c}.197 \\
(.139)\end{array}$ & $\begin{array}{l}-.037 \\
(.187)\end{array}$ \\
\hline Conservative & \multicolumn{4}{|c|}{ Reference } \\
\hline Against Cons & $\begin{array}{l}.108 \\
(.113)\end{array}$ & $\begin{array}{l}.380^{*} \\
(.181)\end{array}$ & $\begin{array}{l}.438^{*} \\
(.182)\end{array}$ & $\begin{array}{l}.429^{*} \\
(.181)\end{array}$ \\
\hline Labour & $\begin{array}{l}-.021 \\
(.125)\end{array}$ & $\begin{array}{l}.411^{*} \\
(.192)\end{array}$ & $\begin{array}{l}.431^{*} \\
(.196)\end{array}$ & $\begin{array}{l}.424^{*} \\
(.194)\end{array}$ \\
\hline LibDem & $\begin{array}{l}.383^{*} \\
(.191)\end{array}$ & $\begin{array}{l}.386 \\
(.300)\end{array}$ & $\begin{array}{l}.451 \\
(.308)\end{array}$ & $\begin{array}{l}.437 \\
(.304)\end{array}$ \\
\hline Undecided & $\begin{array}{c}-.505^{* *} \\
(.168)\end{array}$ & $\begin{array}{l}-.519^{*} \\
(.267)\end{array}$ & $\begin{array}{c}-.440^{+} \\
(.267)\end{array}$ & $\begin{array}{r}-.449^{+} \\
(.265)\end{array}$ \\
\hline Non-voter & $\begin{array}{c}-.621^{*} \\
(.286)\end{array}$ & $\begin{array}{c}-1.05^{+} \\
(.578)\end{array}$ & $\begin{array}{l}-.786 \\
(.569)\end{array}$ & $\begin{array}{l}-.834 \\
(.568)\end{array}$ \\
\hline Missing & $\begin{array}{c}-.740^{* * *} \\
(.088)\end{array}$ & $\begin{array}{c}-.458^{* *} \\
(.144)\end{array}$ & $\begin{array}{c}.125 \\
(.154)\end{array}$ & $\begin{array}{l}.028 \\
(.159)\end{array}$ \\
\hline Cons x Campaign & \multicolumn{4}{|c|}{ Reference } \\
\hline Against Cons x Campaign & & $\begin{array}{c}-.433^{+} \\
(.231)\end{array}$ & $\begin{array}{c}-.449^{+} \\
(.233)\end{array}$ & $\begin{array}{c}-.436^{+} \\
(.232)\end{array}$ \\
\hline Labour x Campaign & & $\begin{array}{c}-.741^{* *} \\
(.255)\end{array}$ & $\begin{array}{c}-.749^{* *} \\
(.260)\end{array}$ & $\begin{array}{c}-.743^{* *} \\
(.258)\end{array}$ \\
\hline LibDem x Campaign & & $\begin{array}{c}.005 \\
(.387)\end{array}$ & $\begin{array}{l}-.134 \\
(.407)\end{array}$ & $\begin{array}{l}-.128 \\
(.407)\end{array}$ \\
\hline Undecided x Campaign & & $\begin{array}{l}.068 \\
(.341)\end{array}$ & $\begin{array}{l}.062 \\
(.337)\end{array}$ & $\begin{array}{l}.077 \\
(.337)\end{array}$ \\
\hline Non-voter x Campaign & & $\begin{array}{l}.638 \\
(.668)\end{array}$ & $\begin{array}{l}.842 \\
(.659)\end{array}$ & $\begin{array}{c}.942 \\
(.661)\end{array}$ \\
\hline Missing x Campaign & & $\begin{array}{l}-.456^{*} \\
(.182)\end{array}$ & $\begin{array}{c}-.470^{*} \\
(.187)\end{array}$ & $\begin{array}{l}-.311 \\
(.199)\end{array}$ \\
\hline Ward & $\begin{array}{l}-.010 \\
(.075)\end{array}$ & $\begin{array}{l}-.006 \\
(.075)\end{array}$ & $\begin{array}{c}.068 \\
(.077) \\
\end{array}$ & $\begin{array}{c}.067 \\
(.077)\end{array}$ \\
\hline Covariates & No & No & Yes & Yes \\
\hline Covariates $\mathrm{x}$ Treatment & No & No & No & Yes \\
\hline $\mathrm{N}$ & \multicolumn{4}{|c|}{$\begin{array}{l}6123 \\
\end{array}$} \\
\hline
\end{tabular}

Note: Clustered standard errors in parentheses, ${ }^{* * *} \mathrm{p}<0.001,{ }^{* *} \mathrm{p}<0.01,{ }^{*} \mathrm{p}<0.05,{ }^{+} \mathrm{p}<0.1$ 
Table A4: Logistic regression of turnout on treatment assignment, conditional on Party ID

\begin{tabular}{|c|c|c|c|c|}
\hline & I & II & III & IV \\
\hline \multirow[t]{2}{*}{ Leaflet } & -.074 & $.270^{+}$ & $.280^{+}$ & .185 \\
\hline & $(.089)$ & $(.160)$ & $(.159)$ & $(.218)$ \\
\hline \multirow[t]{2}{*}{ Leaflet \& Canvass } & $-.183^{*}$ & .069 & .120 & -.264 \\
\hline & $(.092)$ & $(.159)$ & $(.159)$ & $(.217)$ \\
\hline Conservative & \multicolumn{4}{|c|}{ Reference } \\
\hline \multirow[t]{2}{*}{ Against Cons } & .105 & $.380^{*}$ & $.439 *$ & $.429^{*}$ \\
\hline & $(.113)$ & $(.181)$ & $(.183)$ & $(.181)$ \\
\hline \multirow[t]{2}{*}{ Labour } & -.027 & $.411^{*}$ & $.431^{*}$ & $.425^{*}$ \\
\hline & $(.125)$ & $(.191)$ & $(.196)$ & $(.194)$ \\
\hline \multirow[t]{2}{*}{ LibDem } & $.385^{*}$ & .386 & .451 & .438 \\
\hline & $(.190)$ & $(.299)$ & $(.308)$ & $(.304)$ \\
\hline \multirow[t]{2}{*}{ Undecided } & $-.507 * *$ & $-.519^{+}$ & $-.440^{+}$ & $-.449^{+}$ \\
\hline & $(.168)$ & $(.267)$ & $(.267)$ & $(.268)$ \\
\hline \multirow[t]{2}{*}{ Non-voter } & $-.626^{*}$ & $-1.05^{+}$ & -.786 & -.834 \\
\hline & $(.286)$ & $(.578)$ & $(.569)$ & $(.568)$ \\
\hline \multirow[t]{2}{*}{ Missing } & $-.743^{* * *}$ & $-.457^{* *}$ & .126 & .029 \\
\hline & $(.088)$ & $(.144)$ & $(.154)$ & $(.159)$ \\
\hline \multirow{3}{*}{$\begin{array}{l}\text { Cons x Leaflet } \\
\text { Against Cons x Leaflet }\end{array}$} & \multicolumn{4}{|c|}{ Reference } \\
\hline & & $-.592^{*}$ & $.575^{*}$ & $-.566^{*}$ \\
\hline & & $(.268)$ & $(.272)$ & $(.281)$ \\
\hline \multirow[t]{2}{*}{ Labour x Leaflet } & & $-.742^{*}$ & $-.710^{*}$ & $-.705^{*}$ \\
\hline & & $(.288)$ & $(.295)$ & $(.293)$ \\
\hline \multirow[t]{2}{*}{ LibDem x Leaflet } & & .403 & .344 & .360 \\
\hline & & $(.442)$ & $(.472)$ & $(.469)$ \\
\hline \multirow[t]{2}{*}{ Undecided x Leaflet } & & .009 & -.008 & -.001 \\
\hline & & $(.403)$ & $(.396)$ & $(.400)$ \\
\hline \multirow{2}{*}{ Non-voter x Leaflet } & & .343 & .696 & .699 \\
\hline & & $(.775)$ & $(.771)$ & $(.772)$ \\
\hline \multirow[t]{2}{*}{ Missing $\mathrm{x}$ Leaflet } & & $-.533^{*}$ & $-.531^{*}$ & $-.467^{*}$ \\
\hline & & $(.212)$ & $(.218)$ & $(.232)$ \\
\hline Cons x Leaflet \& Canvass & & Refer & ace & \\
\hline \multirow{2}{*}{ Against Cons x Leaflet \& Canvass } & & -.275 & -.324 & -.315 \\
\hline & & $(.279)$ & $(.279)$ & $(.281)$ \\
\hline \multirow[t]{2}{*}{ Labour x Leaflet \& Canvass } & & $-786^{*}$ & $-.838^{*}$ & $-.845^{*}$ \\
\hline & & $(.333)$ & $(.334)$ & $(.336)$ \\
\hline \multirow[t]{2}{*}{ LibDem x Leaflet \& Canvass } & & -.294 & -.498 & -.516 \\
\hline & & $(.460)$ & $(.482)$ & $(.488)$ \\
\hline \multirow[t]{2}{*}{ Undecided x Leaflet \& Canvass } & & .119 & .124 & .157 \\
\hline & & $(.402)$ & $(.396)$ & $(.395)$ \\
\hline \multirow[t]{2}{*}{ Non-voter x Leaflet \& Canvass } & & .935 & .982 & 1.135 \\
\hline & & $(.718)$ & $(.708)$ & $(.717)$ \\
\hline \multirow[t]{2}{*}{ Missing x Leaflet \& Canvass } & & $-.389^{+}$ & $-.417^{+}$ & -.153 \\
\hline & & $(.213)$ & $(.218)$ & $(.232)$ \\
\hline North & -.010 & -.003 & .072 & .069 \\
\hline & $(.075)$ & $(.075)$ & $(.077)$ & $(.077)$ \\
\hline Covariates & No & No & Yes & Yes \\
\hline Covariates $\mathrm{x}$ Treatment & No & No & No & Yes \\
\hline Observations & & $61^{\circ}$ & & \\
\hline
\end{tabular}

Note: Clustered standard errors in parentheses, ${ }^{* * *} \mathrm{p}<0.001,{ }^{* *} \mathrm{p}<0.01,{ }^{*} \mathrm{p}<0.05,{ }^{+} \mathrm{p}<0.1$ 


\section{Door-knock and leaflet versus leaflet only}

In Table A5 we identify the CACE effect of personal canvassing on turnout. We are able to isolate the effect of personal contact with a Conservative canvasser from the effect of the leaflet because all subjects in the two treatment groups received the campaign leaflet. The Complier Average Causal Effects by partisanship, in our case the subjects who answered the door when Conservative canvassers attempted to contact them and hand-over the leaflet personally, are displayed in Table A5. If $Y_{i}$ is turnout, $d_{i}$ indicates whether personal contact with the canvasser was made, $z_{i}$ is treatment assignment either to the leaflet only condition $\left(z_{i}=0\right)$ or the leaflet and canvassing condition $\left(z_{i}=1\right)$, then the two-stage least squares model we estimate for the CACE can be written as:

$$
\begin{gathered}
Y_{i}=\beta_{0}+\beta_{1} d_{i}+\beta_{2} \text { RivalParty }_{i}+\beta_{3} \text { Unattached }_{i}+\beta_{4} d_{i} * \text { RivalPart }_{i}+\beta_{5} d_{i} * \text { Unattached }_{i} \\
+\mu_{i}, \text { in which } \\
d_{i}=\gamma_{0}+\gamma_{1} z_{i}+\gamma_{2} \text { RivalParty }_{i}+\gamma_{3} \text { Unattached }_{i}+\gamma_{4} z_{i} * \text { RivalPart }_{i}+\gamma_{5} z_{i} * \text { Unattached }_{i}+\epsilon_{i}
\end{gathered}
$$


Table A5: Instrumental variable regression of turnout on canvassing instrumented by assignment to canvassing or leaflet condition, conditional on Party ID

\begin{tabular}{|c|c|c|c|c|}
\hline & $\mathrm{I}$ & II & III & IV \\
\hline Canvassing & $\begin{array}{l}.051 \\
(.044)\end{array}$ & $\begin{array}{l}.047 \\
(.042)\end{array}$ & $\begin{array}{l}-.100 \\
(.082)\end{array}$ & $\begin{array}{c}-.158^{+} \\
(.093)\end{array}$ \\
\hline Conservative & \multicolumn{4}{|c|}{ Reference } \\
\hline Rival Party & $\begin{array}{l}-.023 \\
(.027)\end{array}$ & $\begin{array}{l}-.019 \\
(.026)\end{array}$ & $\begin{array}{l}-.035 \\
(.038)\end{array}$ & $\begin{array}{l}-.023 \\
(.037)\end{array}$ \\
\hline Unattached & $\begin{array}{c}-.170 * * * \\
(.022)\end{array}$ & $\begin{array}{l}-.055^{*} \\
(.022)\end{array}$ & $\begin{array}{c}-.189 * * * \\
(.031)\end{array}$ & $\begin{array}{c}-.082^{*} \\
(.033)\end{array}$ \\
\hline Conservative & \multicolumn{4}{|c|}{ Reference } \\
\hline Rival Party x Canvass & & & $\begin{array}{c}.050 \\
(.116)\end{array}$ & $\begin{array}{c}.015 \\
(.111)\end{array}$ \\
\hline Unattached x Canvass & & & $\begin{array}{c}.081 \\
(.100)\end{array}$ & $\begin{array}{c}.128 \\
(.103)\end{array}$ \\
\hline Ward & $\begin{array}{c}.012 \\
(.019)\end{array}$ & $\begin{array}{c}.018 \\
(.018)\end{array}$ & $\begin{array}{c}.011 \\
(.019)\end{array}$ & $\begin{array}{c}.019 \\
(.018)\end{array}$ \\
\hline Covariates & No & Yes & No & Yes \\
\hline Covariates x Canvass & No & No & No & Yes \\
\hline $\mathrm{N}$ & \multicolumn{4}{|c|}{3786} \\
\hline
\end{tabular}

Note: Clustered standard errors in parentheses, ${ }^{* * *} \mathrm{p}<0.001,{ }^{* *} \mathrm{p}<0.01,{ }^{*} \mathrm{p}<0.05,{ }^{+} \mathrm{p}<0.1$ 